\title{
Social Interactive Entropy and Interaction in the Language Teacher Education Classroom
}

\section{Entropia sociointerativa e interação na sala de aula de formação de professores de línguas}

Rafael Vetromille-Castro*

Universidade Federal de Pelotas (UFPel)

Pelotas - Rio Grande do Sul/Brasil

\begin{abstract}
This paper has as core ideas the assumption that interaction is essential for knowledge construction and the claim that groups of individuals in learning contexts can be seen as complex adaptive systems (CAS). Some different, but congruous views on the classroom as a complex adaptive system are presented and the phenomenon which is constantly at work and affecting each and every CAS - the entropy - is brought to discussion. A specific type of entropy for social groups, defined as social interactive entropy, is also introduced as an attempt to promote reflection on how this phenomenon affects the behavior of a classroom under a complex perspective and how it influences such a social CAS by providing or restricting conditions for interaction and, hence, learning to emerge.
\end{abstract}

KEYWORDS: complex adaptive systems; interaction; language teacher education; social interactive entropy; language learning classroom.

RESUMO: Este trabalho tem como ideias centrais o pressuposto de que a interação é essencial para a construção do conhecimento e a afirmação de que grupos de indivíduos em contextos de aprendizagem podem ser vistos como sistemas adaptativos complexos (SAC). Alguns pontos de vista diferentes, mas congruentes sobre a sala de aula como um SAC são apresentados, e o fenômeno que está constantemente em ação e afetando todo e qualquer $S A C$ - a entropia - é trazido à discussão. Um tipo específico de entropia para grupos sociais, definido como entropia socio-interativa, também é apresentado com o objetivo de promover a reflexão sobre como tal fenômeno afeta o comportamento de uma sala de aula, sob a perspectiva complexa, e influencia tal SAC social, quando propicia ou restringe condiçôes para que a interação ocorra e, consequentemente, para que a aprendizagem emerja.

PALAVRAS-CHAVE: sistemas adaptativos complexos; interação; formação de professores de línguas; entropia sociointerativa; sala de aula de aprendizagem de línguas.

*vetromillecastro@gmail.com 


\section{Introduction}

The assumption that learning is socially constructed is not new, and its underlying idea is that interaction is essential to knowledge construction. This is well accepted in language learning and language acquisition, when, according to Ellis (1994, p. 143-89), "[...] acquisition is seen as a product of the complex interaction of the linguistic environment and the learner's internal mechanisms [...]". Ellis also supports a more social perspective on language learning by saying that "[...] verbal interaction is of crucial importance for language learning as it helps to make the 'facts' of the L2 salient to the learner".

Also, when language learning methodologies developed and used in the last 30 years, e.g. Communicative Language Teaching (CLT), have as core principle the development of learners' communicative competence (CANALE; SWAIN, 1980; CANALE, 1983), we realize the central role interaction plays not only in the learning process - which is expected to be developed through communication opportunities - but especially in the purpose for people to learn a language.

If we look at more recent studies on language, as those based on Chaos/ Complexity Theory (C/CT), we can also find interaction as a central concept for language development, not only implicitly when researchers (THE FIVE GRACES GROUP, 2009, p. 2) say that "[l]anguage has a fundamentally social function", but also when they support the assumption that language is a Complex Adaptive System (CAS), which (a) consists of multiple agents (the speakers in the speech community) interacting with one another; (b) is adaptive and, being so, generates future behavior based on agents' past and current interactions; and (c) has its structure emerged "from interrelated patterns of experience, social interaction, and cognitive processes".

Interaction, therefore, should be central in any language learning classroom, not only that of face-to-face (F2F) situations, but especially that of distance/digital environments.

In this paper, I assume interaction as an essential element for knowledge construction and claim that groups of individuals in learning contexts can be seen as CASs. Along the enterprise, I present and debate some different, but congruous views on the classroom as a complex adaptive system (DAVIS; SIMMT, 2003; BOWSFIELD, 2004; VETROMILLE-CASTRO, 2007). Having these views as an assumption, I bring to discussion the phenomenon which is constantly at work and affecting each and every CAS - the entropy - which, in the case of social groups, has been defined as social interactive 
entropy (VETROMILLE-CASTRO, 2007; 2008). Understanding how this phenomenon influences the behavior of a classroom under a complex perspective seems to be important for language educators to deal with different moments in the life of such a social CAS in order to provide conditions for interaction and, hence, learning to emerge.

\section{The (language learning/EFL teacher education) classroom as a Complex Adaptive System: research implications}

In recent years, researchers have been encouraged and/or moved to take a look at language learning phenomena and contexts by using "different lenses", or perspectives, e.g. C/CT. In this section, I will refer to some authors who have tried to analyze the classroom (EFL/teacher education/virtual ones included) as CASs. In 2007, Cameron and Larsen-Freeman developed some initial but insightful considerations on language classrooms as CASs. Although they did not discuss in depth how similar both entities can be, they signaled some major features classrooms and CASs share, such as unpredictability, selforganization and non-linearity:

Describing classroom activity in terms of interacting complex systems helps us see how teachers and students can co-adapt to stable patterns of teaching behaviour, motivation and participation that may not always be supportive to learning (p. 237-238).

Unpredictability as a CAS feature refers to the fact that such systems present random behaviors that cannot be foreseen. Even when CASs adopt a regular, orderly trajectory, not only there is no guarantee that such a behavior will last, but also it is unknown the moment when the system will reach the edge of chaos and start reorganizing elements and new trajectories. Still, unpredictability is directly related to the interconnectedness of system components that brings about the impossibility to predict the vast array of potential relationships in a CAS. Also, as Larsen-Freeman (1997, p. 144) says, CASs behavior is unpredictable especially due to their dependence on initial conditions, which may cause dramatic, systemic modifications when a slight change occurs.

Such systemic modifications happen at a regular basis in an everlasting process of self-organization. CASs are constantly struggling to absorb new behavior and elements, since they are not only sensitive to initial conditions and feedback, but also open to external influence. It can only be speculated 
what kind of new system will result from the self-organization generated by new and unexpected elements and that is so because CASs are non-linear. Nonlinearity refers to the disproportionate relation between cause and effect. A repeated behavior may apparently cause no perturbation in the system, until the moment it unexpectedly does. Essential to highlight is the fact that these and other CAS features are under constant interplay, mutually affecting one another and causing systemic changes.

In the same line as Cameron and Larsen-Freeman (2007), and trying to find answers that would allow teachers "to redirect the energy and attention of the already existing social collective towards powerful learning opportunities where the classroom is experienced as a collective learning system", Bowsfield (2004, p. 147) argues that classes evolve into emergent self-organizing systems. Although in a basic level of C/CT concepts (as the author states), the analysis brings to light insightful reflection on how similar classes and CASs can be by referring to Capra (1996; 2002), Davis and Sumara (1997), but especially Davis and Simmt (2003) and their five conditions for a system to emerge: internal diversity, redundancy, decentralized control, enabling constraints and neighboring interactions. In other words, according to Bowsfield (op.cit.), classes would emerge when the agents' differences stimulate new and innovative responses, their similarities can feed immediate interaction, control over the actions is shared by not one single, but several agents, and interactions are ruled by a set of constraints, which limit systemic actions, but allow for a plethora of agent behaviors, similarly to the rules of a game. By having a close look at Bowsfield's (2004) and Davis and Simmt's (2003) considerations, the permeating idea of interaction can be seen as essential to system (classroom) emergence.

The perspective of classrooms as CASs was also investigated and supported by Vetromille-Castro $(2007 ; 2008)$. A group of individuals in an online in-service teacher education classroom was analyzed and, through the application of not only the complex systems features originally presented by Larsen-Freeman (1997) but also Bertalanffy's General System Theory (1973), evidence that classrooms can be seen under the CASs metaphor was shown, especially due to their essential energy - interaction - and their susceptibility to entropy. Both interaction and entropy will be dealt along this paper.

In 1997, Larsen-Freeman had originally presented and discussed, in applied linguistics, the following characteristics in order to define complex 
systems: ${ }^{1}$ they are dynamic, complex, nonlinear, chaotic, unpredictable, sensitive to initial conditions, open, self-organizing, feedback sensitive, adaptive. Having such characteristics as a background, Vetromille-Castro tracked classroom elements and behaviors that would allow us to understand such educational context as a complex system. It was observed that the way actions develop in a given learning task, with different individuals (teachers and students) performing at varied paces and frequency, moving from moments of total silence to effervescent dialogical situations might illustrate the dynamism, the complexity and chaos that permeate any given class. The disproportionate relationship between "teaching" (or "exposure to content") and learning make evident the nonlinear aspect of complex systems in a classroom (as non-linearity was referred to before in the text). Such a disproportion would resonate in Larsen-Freeman and Cameron's Complex systems and applied linguistics (2008, p. 252) when they said that "teaching does not cause learning". The view of groups of individuals in learning contexts as complex systems is also strengthened when we see learners and teachers adapt and organize their actions to factors not directly related to the educational experience ${ }^{2}$ originally, but that surely influence behaviors in the group - the classroom is open, self-organizing, adaptive, unpredictable. It is also argued (VETROMILLE-CASTRO, 2007) that both course and lesson plans (even when they are open-ended) trigger a series of unpredictable given events, but not others. Such plans, as well as the way teachers and students start tasks, could be seen as initial conditions for (interactional) behaviors to emerge.

In the same text, comparison is made between classrooms and CASs by referring to Bertalanffy's General System Theory (1973), in which some other complex system features are presented. The first idea from Bertalanffy brought

\footnotetext{
${ }^{1}$ In that paper, the author had not used the definition complex adaptive system (CAS). However, in subsequent texts the term CAS - which is more comprehensive and adequate to the area - started being used interchangeably. In the present paper, difference will not be made between complex adaptive system, complex system and dynamic system.

${ }^{2}$ Just to illustrate, a group of students and teacher in an elementary school in northern Brazil was having classes under a mango tree last year, due to extreme heat in class (http://notapajos.globo.com/lernoticias.asp?id=44640\&noticia=Sem\% 20sala\%20 de\%20aula,\%20alunos\%20estudam $\% 20$ embaixo\%20da\%20mangueira). While they had classes, they would also have mango fruit. For the lack of proper classrooms, students in southern Brazil had to have classes inside an iron shipping container (http://agente65.blogspot.com.br/2009/04/escola-de-lata-cara-de-pau.html).
} 
closer to the classroom is that of "the whole is more than the sum of its parts", meaning that constitutive characteristics cannot be explained by the analysis of isolated parts.

Bertalanffy's theory is also regarded when the definition of "system" is presented. In the General System Theory, a system can be defined as a complex of elements in interaction, with three different distinctions according to their number, species or relations. Bertalanffy goes on and says that complexes of number and species can be understood by the sum of its elements and, thus, have summative characteristics. Such characteristics do not change either when the elements are isolated or when they are in the system. I see this kind of complex or, simply put, system, as engine parts built together to make a machine function. These parts work together but are not modified by the others, and, if one of them is broken, it can be replaced by a similar piece. It does not seem that those two kinds of complexes can be used metaphorically to look at (language learning) classrooms. However, when it comes to systems which are distinct due to the relations between the elements, the interactions and the elements' characteristics are essential for one to understand the system. In this kind of complex, according to Bertalanffy (1973, p. 83), the characteristics are constitutive, which "depend on specific relations within the system". ${ }^{3}$ It seems quite reasonable to say that the behaviors in a classroom chiefly emerge from the relations individuals establish with one another, not from the mere existence of elements. In this line, I follow the assumption made in Vetromille-Castro (2007), namely, a classroom is far more than a group of individuals, a teacher, books and desks - a classroom can only be seen as a learning locus when these and other elements are engaged in interaction. Although Bertalanffy did not use the same term as Larsen-Freeman (1997), Davis and Simmt (2003) and Bowsfield (2004) did, it is clear that the author was referring to CASs, especially because he also defined those complexes as open, living under constant disequilibrium and self-organization. Such features were primarily studied in biological systems, but Bertalanffy believed those concepts and findings could also be applied in social sciences and now several researchers refer to General System Theory in interdisciplinary studies of systems in Anthropology, Economics, Psychology, among others, Language Learning/Teaching and Language Teacher Education included.

${ }^{3}$ Translated passages in this paper are under my responsibility. 
Having defined what a CAS is and how the classroom has been viewed as a CAS by different researchers, I take a closer look at Vetromille-Castro (2007)'s assumptions and start by approaching the author's definition of "classroom", which would be any group of learning-driven individuals interacting in a given context. Although this referred research was focused on online learning environments and considered online groups and its behaviors as a CAS, I have seen F2F groups behave as and show features of such systems. So, in this paper, although I may allude to online contexts, I will take classrooms in general as CAS, no matter the context they are inserted in. What matters to me from now on is how the CAS "classroom" responds to its specific entropy - social interactive entropy - and the role of interaction in the life of this system. By understanding the system responses, I believe some considerations can be made towards setting interaction-rich educational contexts.

\section{Social interactive entropy, interaction and learning: pedagogical implications}

Before approaching the concept of social interactive entropy and its pedagogical implications, it is important to deal with the general and original concept "entropy" from Physics. Entropy has its origins in the early studies on the amount of energy that is lost in certain phenomena, such as friction of elements or convection processes. Although the term has only emerged in 1865 , coined by the German mathematician and physicist Rudolf Clausius (18221888) due to its similarity to the word energy - words which were, according to him, closely related - the discussion about the process that entropy describes already happened in 1698, when engineers such as Thomas Savery built the first internal combustion engines. However, such devices were ineffective in converting energy into work. In other words, there was little result and a huge waste of energy. So it can be said that the inefficiency of engines led, somehow, to deeper studies that have given rise to the concept "entropy".

Originally, entropy is a concept linked to the Second Law of Thermodynamics, which deals with the transformation of energy into work and says that heat transfer always occurs from a warmer to a cooler body, until the temperature of both is equal. During the transfer, part of the energy is dissipated, lost in the environment. In general terms, entropy can be considered as this amount of energy which is dissipated in the process and does not change into anything. Some authors, such as Ruelle (1993), implicitly lead us to understand entropy as the Second Law of Thermodynamics itself, 
however, most researchers (GLEICK, 1989; LAYZER, 1990; ALTEKAR, 1998) support that the first is only an element in the discussion of the Second Law, although one of its fundamental concepts.

Although it is a concept with origins in Thermodynamics, entropy has ramifications in other areas such as Economics and Theories of Evolution, with specific implications. The most prominent is perhaps the one linked to Information Theory, the Information entropy or Shannon entropy, which concerns to the loss of information in telephone lines. By taking into consideration the similarities between those different concepts of entropy, the connection between the terms of Thermodynamics and Information Theory seems evident: both consider what is lost in a system, be it energy, be it information.

The term "entropy" has other ramifications, even in Thermodynamics, such as: Gibbs and Boltzmann entropy, both related to statistical mechanics; Tsallis entropy, which is a generalization of Gibbs and Boltzmann entropy and is also linked to statistical mechanics; the metric or Kolmogorov-Sinai entropy, related to the study of unstable systems and Ergodic Theory; and the black hole entropy, connected to both Physics and Cosmology, and dealing with the energy dissipated when black holes gobble matter. ${ }^{4}$ Although each kind of entropy mentioned deals with specific phenomena in specific areas, all of them have as core assumptions energy loss and increase in disorder.

At first, Thermodynamics dealt with entropy in closed systems (RUELLE, 1993). In this context, when the particles or elements of a system interact, entropy tends to increase until the system perishes due to the total loss of useful energy which can be transformed into work. An example that illustrates the fact that entropy in a closed system always increases is the hypothesis Physics presents to the end of the Universe. It is argued that, since the Big Bang, the closed system "Universe" is in a constant process of increasing entropy, that is, an increase in energy dispersion. There will come a time when the Universe will reach its maximum entropy and cease to exist, a phenomenon called "heat death".

${ }^{4}$ In the 1970s, Stephen Hawking showed through mathematical evidence that black holes emit radiation when they gobble matter. Recently, the Russian physicist Vladimir Belinski fought such evidence after having developed 10-year research. However, he has not presented solution to the question. More details (in Portuguese) in: <http://agenciact.mct.gov.br/index.php/content/view/41458.html>. 
Entropy is also present in open systems, e.g. CASs, and how it manifests itself in open contexts corroborates our view. In any system, energy is in constant dissipation. However, in closed systems, there is no compensatory means for replacing the energy lost, so entropy and disorder always increase. If we had a graphic showing energy behavior in a closed system, we would have something very close to a continuous downward line. Nevertheless, in an open system, there is the possibility of external energy being integrated, offsetting energy dissipation and slowing entropy down. This possibility of offsetting energy loss characterizes the system, according to Ruelle (1993, p. 64), as a dynamic one. Two aspects are, however, important to be emphasized: first, in open systems there may be a slowdown in this behavior, but there is no guarantee that it will happen. Differently, external elements can act on the system and accelerate entropy. The second aspect, which is somehow intertwined with the first, refers to the fact that entropy, both in open and in closed systems, is always present. There may be deceleration in its increase, influenced by external factors (in the case of open systems), but the loss of energy and increase in disorder are always happening.

Sharing with authors from the various areas mentioned before the core assumptions related to the general and original concept of entropy, namely, constant energy loss and increase in disorder, in 2007 a new definition of entropy was proposed (VETROMILLE-CASTRO, 2007, p. 93) in order to deal with classrooms as CASs. In such systems, the energy being dissipated would be interaction. Having groups in virtual learning environments as research context, it has been stated that interindividual interaction plays an essential role in the formation and maintenance of CAS. In other words, interactional flows of messages were seen as the "fuel", the energy of such complex systems. While there are messages being exchanged (so, while there is energy), the group exists as a system. When interactional flows decrease or cease, participants disperse ${ }^{5}$ and the system succumbs. This movement of dispersion would be, it has been argued, the manifestation of disorder. Such a complex perspective on interaction brings to light some implications to define what a classroom really is. In my point of view, one of the main contributions to language educators is the fact that a group of individuals simply sitting in a room and having a teacher talking uninterruptedly for an hour or so does not constitute (or emerge as) a classroom if there are no

\footnotetext{
${ }^{5}$ It is relevant to highlight that "participants' dispersion" does not mean only "classroom evasion". This dispersion can refer to situations in which there is no interaction, although individuals may be sharing the same environment.
} 
interactional behaviors. A classroom would be, hence, a living organism, fighting for survival through interaction among elements, trying not only to find similarities and harmonize diversity, but also under constant adaptation with the outside, in an unpredictable, self-organizing, "entropy-compensating" behavior. Having said that, I go on to debate some aspects related to interaction by referring to three moments in the life of CASs, which have also been identified (2007).

Before moving on to the next section, it is essential to say that I recognize that the assumptions on social interactive entropy are in on a metaphorical basis and I know that such a perspective is criticized by some authors, like Gregg (2010) in his Shallow draughts: Larsen-Freeman and Cameron on Complexity. However, I do not share this view, since I agree with Bowers (1990 apud MALLOWS, 2002, p. 3) when the author says "you don't see something until you have the right metaphor for it". Also, in the same line, I believe metaphors are important for comprehending new theoretical constructs, as Larsen-Freeman and Cameron (2008, p. 11) state:

[m] etaphors are not just literary tools for ornamenting language; they are indispensible to the human mind. Whenever we have to contemplate the abstract, voice the difficult, or make sense of the complicated, we turn to metaphor.

\section{The classroom as a CAS: living on the edge}

As I recalled at the beginning of this paper, interaction is essential to knowledge construction. This assumption is, in my point of view, in total agreement with the metaphorical perspective of a classroom as a CAS, since interactional flows would prevent the system from succumbing to social interactive entropy. In other words, it seems to be fair to say that a classroom in which interaction does not emerge would be a lifeless system and, therefore, could not be - in its essence - a learning locus.

In this scenario, a question arises: why do individuals interact? In order to answer the question, I find especially helpful to refer to three moments observed in the life of CASs (VETROMILLE-CASTRO, 2007). This study ${ }^{6}$

\footnotetext{
${ }^{6}$ Further details on the research developed may be found both at the author's $\mathrm{PhD}$ dissertation (<http://www.lume.ufrgs.br/bitstream/handle/10183/14754/ 000666344.pdf?sequence $=1>$ ) and at a paper published in Revista Brasileira de Linguistica Aplicada in 2008 (<http://www.periodicos.letras.ufmg.br/rbla/\#download\&150.pdf>).
} 
was concentrated on three editions of an extension university course on developing CALL materials through an authoring system. The course was developed totally at a distance in a virtual learning environment (VLE). The groups of students consisted of pre-service and in-service language teachers. Groups were heterogeneous in respect to prior contact with digital technology, since there were both students with experience in distance education and those who had just started using computers and, due to this fact, had difficulty in managing files and understanding spaces in the virtual environment. Each edition of the course lasted for 10 (ten) weeks, and participants interacted primarily in the VLE's weekly fora and in each student's portfolios. ${ }^{7}$ Research was developed by analyzing such interactions and trying to identify the social values $^{8}$ (PIAGET, 1973) that motivated interpersonal contact and resulted in the emergence of the classroom as a CAS.

Having analyzed a group of individuals in an online in-service teacher education classroom through weekly forums in a virtual learning environment, it has been realized that such a CAS had been through three different moments, labeled as: maximum entropic force, systemic resistance and systemic surrender (VETROMILLE-CASTRO, 2007). These moments could be verified through the analysis of interactional flows in the forums of three different editions of the same 10-week course (Graphic 1):?

\footnotetext{
${ }^{7}$ Occasionally, students also interacted via e-mail messages, but the researcher had no access to this content.

${ }^{8}$ It has been observed that interaction was motivated mostly by social values such as collaboration and autonomy, which were narrowly connected to the concept mutual benefit (PIAGET, 1973).

${ }^{9}$ Graphics 1 and 2 were reproduced from Vetromille-Castro's $\mathrm{PhD}$ dissertation, but translated into English for this paper.

${ }^{10}$ This term and others from Piaget's work in this paper have been translated into English by me, since I had no access to an English version of his book Sociological Studies (1973).
} 
GRAPHIC 1

Total interactional flow along 10 weeks

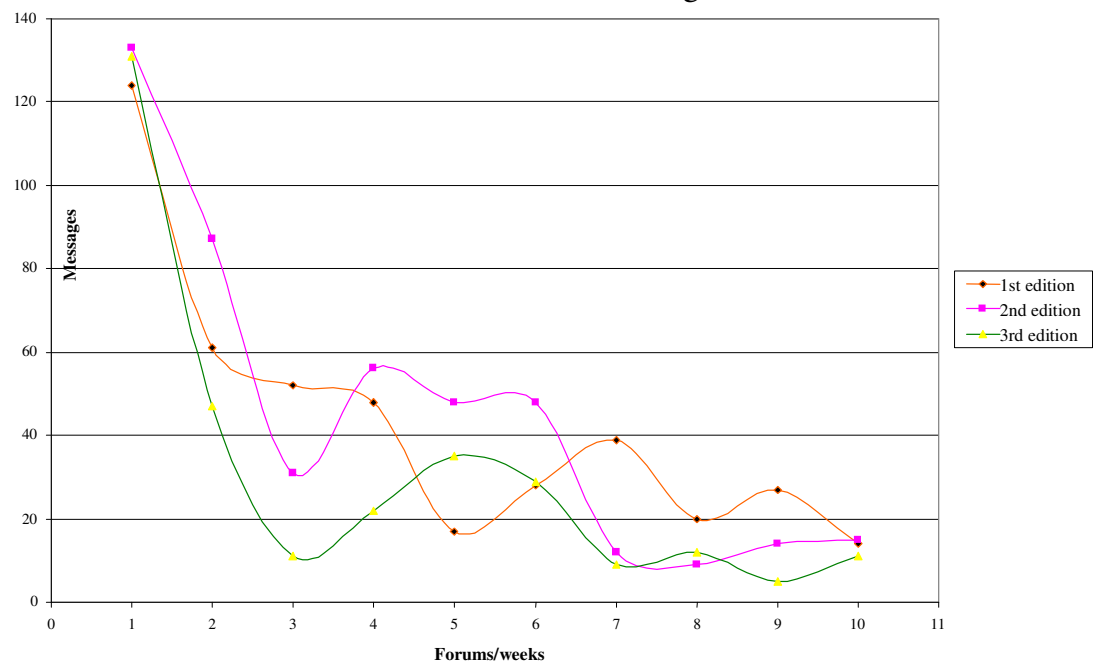

Source: Vetromille-Castro, 2007, p. 95

We can see similar interactional flows in the three editions of the course. There is a strong flow of messaging on the first week, surpassing 120 messages. On the second week, there is a still high flow of messages (between 47 and 87), but already showing a decline, which is initially abrupt and accelerated (second and third weeks), but it becomes softer and decelerated between the third and seventh week. On the last three weeks of the course, the number of messages keeps on falling, reaching almost zero.

Below, in Graphic 2, we have the trend in the volume of interactions of each edition, reinforcing that they show quite similar behaviors: 


\section{GRAPHIC 2}

Trend in the total volume of interactions

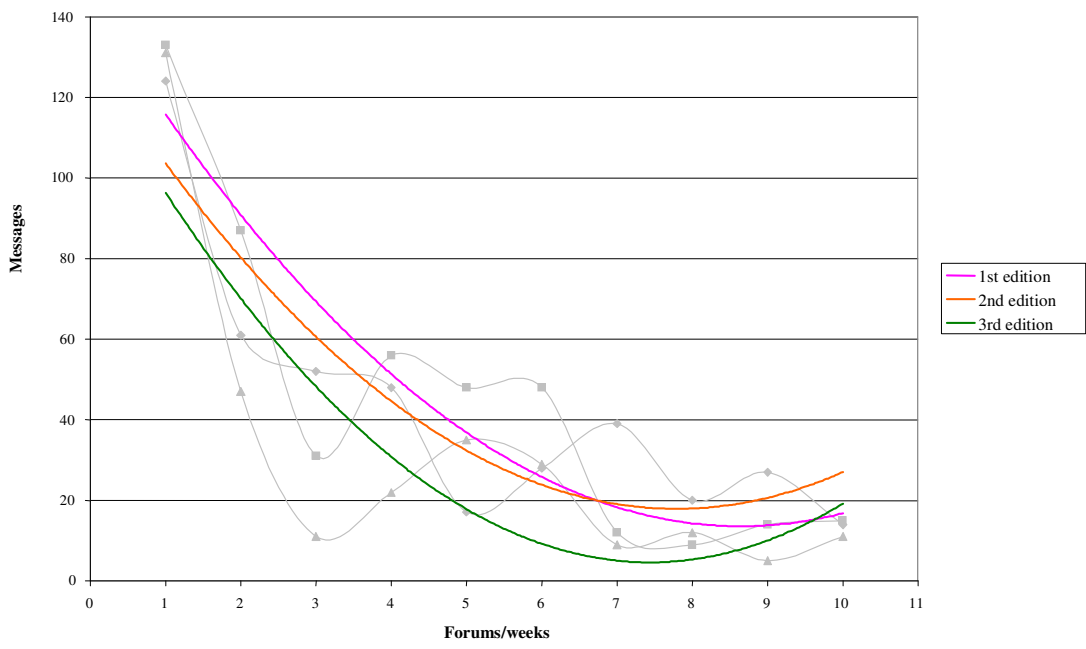

Source: Vetromille-Castro, 2007, p. 96

The first two weeks are characterized by a strong flow of messages which is then softened and represented by a gradual decrease tending toward stability, showing a slight increase at the end. Looking at Graphics 1 and 2, social interactive entropy can be clearly seen. There is an initial, short period with a strong flow of messages and an abrupt fall until the beginning of the following period. This first period was defined as maximum entropic force because most of those messages, yet abundant, are not addressed to any specific individual or group and do not generate interaction. Due to this lack of interactive purpose, the author argues, the number of messages falls dramatically until the third week. That is, messages that were potentially interactive cease to exist, revealing energy loss and increase in disorder in this CAS.

From the third to approximately the seventh week, it is possible to realize the period of systemic resistance. The hills and valleys in Graphic 1 show the CAS struggling to survive - there are weeks on which individuals interact more than on others, revealing the constant and typical disequilibrium of a CAS. The chaotic behavior in this period is a potentially flourishing context for learning to occur, since the edge of chaos is the zone of maximum creativity, as some authors state or suggest (PAIVA, 2011, p. 193; WALDROP, 1993, p. 12; GLEICK, 1989). 
Graphic 1 also shows that the interactional flow in those three groups analyzed tended to zero from the eighth to the tenth week, period labeled as systemic surrender. It has been reported (op. cit.) that learners from those courses had already achieved the expected goals and, having very few questions to answer, had no motivation to interact. Thus, as previously argued, when interaction ceases, the system succumbs.

The author remarks that those periods may not occur in every CAS exactly as they did in the courses studied. If there are no compensatory behaviors for interaction loss, it is stated, CASs may move from maximum entropic force to systemic surrender.

When I look at those three systemic periods in the attempt to answer the question "why do individuals interact?", the second moment - the systemic resistance - seems especially interesting to me, due to the fact that it was the period in which those systems were fighting social interactive entropy, by compensating energy (interaction) lost during maximum entropic force.

Although Vetromille-Castro recognizes the complexity and variety of aspects orbitting around the reasons for people in educational contexts to interact, it has been verified that individuals from those groups interacted mostly from the third to the seventh week because the course plan in each period demanded from them collaborative attitudes in order to accomplish given tasks. In that sense, weekly tasks functioned as initial conditions - or enabling constraints, according to Davis and Simmt (2003) - that provided individuals - and the system - with a potentially rich context for interaction to emerge. Still, it is relevant to mention the identification of message exchanges motivated by what Piaget (1973) referred to as mutual benefit ${ }^{10}$ a reward individuals would profit when they are in a mutual valuing relationship, that is, when they see each other as real peers, sharing a common set of social, qualitative values. Such similarities agree with one of Davis and Simmt's conditions (2003) for a system to emerge, namely, redundancy, which would allow individuals' immediate interactions.

When hills and valleys are shown in Graphic 1, it is seen the system struggling to survive, what represented, in practical terms, the teacher's efforts and interventions, motivating students and adjusting tasks, in order to trigger more autonomous and collaborative attitudes on a new week after having faced a lower-interactional flow period on the week before. In time, those interventions show the teacher not abrogating the "responsibility for managing their students' learning in a way consonant with the negotiated and mutable 
goals of instruction" (LARSEN-FREEMAN; CAMERON, 2008, p. 252). Such efforts also portrait not only a triggering action for systemic selforganization, but also the unpredictability in the system and its susceptibility to external factors, if we take into consideration the fact that new tasks were proposed and modified the original course plan.

\section{Transitory, final remarks}

In this paper, I did not intend to - and I am aware of the fact that I may not - be conclusive and establish "general truths" on classrooms as CAS, since $\mathrm{C} / \mathrm{CT}$ paradigm differs from classic, linear view of science, on which applied linguistics has been mostly based. I share Larsen-Freeman and Cameron's dissatisfaction with the "decontextualizing, segregating, and atemporalizing, $[\ldots]$ in the limiting assumptions in applied linguistics" (2008, p. 252), and, instead, I attempted to contribute to a different perspective of educational/ language learning contexts, in which there is a variety of elements in a complex, unpredictable relationship of mutual and constant influence. This fact has several implications for activities that depend primarily on interaction, as learning and teaching are. Larsen-Freeman and Cameron (2008, p. 253) provide us with a brief but clear description of complex system behavior, which seems particularly appropriate for the point I tried to make in this paper:

We recognize that a dynamic system can continue to maintain its order, indeed give rise to new order, through self-organization, if it is open to energy from outside itself. The trajectory of a complex dynamic system, though, is characterized by non-linearity due to the interactions of its agents and elements and the fact that they change, as does their relationship within the complex system. It is the variability of the system that shows that it has the potential for further change and development. Complex systems also construct the contexts of which they are a part.

Although the authors were not referring to classrooms, but language using as CAS, the passage highlights the importance of interaction to any kind of complex, dynamic system. Also, it is remarkable the essentiality of energy for systems' maintenance and development - or, as I argued, of interaction for systems to fight social interactive entropy, survive and evolve. In the passage, it is also possible to infer that difference and conflict are indispensable for a system to develop, a resonant idea with Davis and Simmt's (2003) conditions 
diversity and enabling constraints. Thus, by looking at classrooms as CASs (even metaphorically) and realizing the effects and consequences CAS characteristics and social interactive entropy exert on educational social groups, I assume that there will not be ultimate answers for the language classroom, but a broader and less blurred horizon lo look at when it comes to the comprehension of factors and behaviors that may influence knowledge construction.

\section{References}

ALTEKAR, E. V. Arrow of time: towards a new epistemology of science. In: WORLD CONGRESS OF PHILOSOPHY, 20, 1998, Boston, Massachusetts. Proceedings... Boston: Paideia Project Online, 1998. Available at: <http:// www.bu.edu/wcp/Papers/TKno/TKnoAlte.htm>. Retrieved July 312012. BERTALANFFY, L. V. Teoria geral dos sistemas. Petrópolis: Vozes, 1973. 351 p. BOWSFIELD, S. Complexity in the English language arts classroom: prompting the collective. In: COMPLEXITY SCIENCE AND EDUCATIONAL RESEARCH CONFERENCE, 2004, Chaffey's Locks, Canada. Proceedings... Chaffey's Locks, Canada, p. 147-154.

CAMERON, L.; LARSEN-FREEMAN, D. Complex systems and applied linguistics. International Journal of Applied Linguistics, v. 17, p. 226-240. 2007. CANALE, M. From communicative competence to communicative language pedagogy. In: RICHARDS, J. C.,; SCHMIDT, R. W. (Eds.). Language and Communication. London: Longman, 1983. p. 2-27.

CANALE, M.; SWAIN, M. Theoretical bases of communicative approaches to second language teaching and testing. Applied Linguistics, Oxford, v. 1, n. 1, p. 1-47, 1980.

CAPRA, F. The Hidden Connections: A Science for Sustainable Living. New York: Anchor Books, 2002.

CAPRA, F. The Web of Life: A New Scientific Understanding of Living Systems. Toronto, Canada: Anchor Books, 1996.

DAVIS, B.; SIMMT, E. Understanding learning systems: mathematics education and complexity science. Journal for Research in Mathematics Education, v. 34, n. 2, p. 137-177, 2003.

DAVIS, B.; SUMARA, D. Cognition, Complexity, and Teacher Education. Harvard Educational Review, v. 67, n. 1, p. 105-125, 1997.

ELLIS, R. The study of second language acquisition. Oxford: Oxford University Press, 1994. $832 \mathrm{p}$. 
GLEICK, J. Caos: a criação de uma nova ciência. 16. ed. Rio de Janeiro: Campus, 1989. 310 p.

GREGG, K. R. Review article: Shallow draughts: Larsen-Freeman and Cameron on Complexity. Second Language Research, v. 26, n. 4, p. 549-560, 2010.

LARSEN-FREEMAN, D. Chaos/complexity science and second language acquisition. Applied Linguistics, Oxford, v. 18, n. 2, p. 141-165, 1997.

LARSEN-FREEMAN, D.; CAMERON, L. Complex systems and applied linguistics. Oxford: Oxford University Press, 2008. 287 p.

LAYZER, D. Cosmogenesis. Oxford: Oxford University Press, 1990. 336 p.

MALLOWS, D. Non-linearity and the observed lesson. ELT Journal, Oxford, v. 56, n. 1, p. 3-10, 2002.

PAIVA, V. L. M. O. Caos, complexidade e aquisição de segunda língua. In: PAIVA, V. L. M. O; NASCIMENTO, M. (Ed.). Sistemas adaptativos complexos: lingua (gem) e aprendizagem. 2. ed. Campinas: Pontes, 2011. p. 187-203.

PIAGET, J. Estudos Sociológicos. Rio de Janeiro: Forense, 1973.

RUELLE, D. Acaso e caos. 2. ed. São Paulo: Editora da Universidade Estadual Paulista, 1993. 224 p.

THE FIVE GRACES GROUP. Language is a complex, adaptive system: position paper. In: ELLIS, N. C.; LARSEN-FREEMAN, D. (Ed.) Language as a complex adaptive system. - Language Learning $60^{\text {th }}$ anniversary special issue. WileyBlackwell, v. 59, n. 1, p. 1-26, 2009.

VETROMILLE-CASTRO, R. A interação social e o benefício recíproco como elementos constituintes de um sistema complexo em ambientes virtuais de aprendizagem para professores de linguas. 2007. 226 f. Tese (Doutorado em Informática na Educação) - Programa de Pós-Graduação em Informática na Educação, Universidade Federal do Rio Grande do Sul, Porto Alegre, 2007. Available at: <http://www.lume.ufrgs.br/bitstream/handle/ $10183 / 14754$ / 000666344.pdf?sequence=1>. Retrieved December 202012.

VETROMILLE-CASTRO, R. Consideraçôes sobre grupos em ambientes virtuais de aprendizagem como sistemas complexos. Revista Brasileira de Linguistica Aplicada (Impresso), v. 8, n. 1, p. 211-234, 2008. Available at: <http://www.periodicos.letras.ufmg.br/rbla/\#download\&150.pdf>. Retrieved December 202012.

WALDROP, M. M. Complexity: the emerging science at the edge of order and chaos. New York: A Touchstone Book, 1993. 384 p.

Recebido em 01/09/2012. Aprovado em 04/02/2013. 